\title{
SEISMIC BASE ISOLATION FOR REDUCING SEISMIC RISK OF ARCHITECTURAL HERITAGE BUILDINGS
}

\author{
Prof. Dr. Vojko Kilar ${ }^{1}$ and Dr. Simon Petrvočič ${ }^{2}$ \\ ${ }^{1}$ University of Ljubljana, Faculty of Architecture, Slovenia. \\ E-mail:vojko.kilar@fa.uni-lj.si, simon.petrovcic@fa.uni-lj.si
}

\begin{abstract}
The paper analyses the applicability of seismic base isolation made of elastomeric bearings for the seismic mitigation of architectural heritage buildings. Due to the inestimable cultural and historical significance any remedial measures into such objects must be selected with care and are usually very limited. In an ideal situation only interventions with minimum visual impacts on the object and maximum potential for restoring its cultural values would be implemented. Historical structures were usually not designed accounting seismic hazard and might be seismically more vulnerable as modern buildings. The paper deals with seismic base isolation as a technique for increasing the seismic resistance of architectural heritage buildings made of unreinforced masonry. Typical base isolation devices represent special bearings that are usually installed bellow the foundations of the structure. If the isolation system is properly designed it can eliminate the need for using more invasive retrofit measures and techniques. The paper presents a relatively simple and computationally less demanding technique for the modelling and analysis of regular unreinforced masonry (URM) structures. This technique is based on the equivalent frame approach, while the complex seismic failure mechanism of masonry piers is expressed by a single failure mode interaction surface (an "FMI surface"), taking into account the influence of variation in the pier's vertical loading, and it's bending moment distribution. A single failure mode interaction plastic hinge (an "FMI hinge") for each masonry frame element is introduced by combining specific failure modes, taking into account their minimum envelope. In the final part of the work a case study of using base isolation for the seismic retrofitting of an existing three-story masonry building has been conducted. Some results obtained by the N2 method comparing the damage in fixed based and base isolated variant of the test building demonstrate the potential of used techniques for the seismic protection of masonry heritage buildings.
\end{abstract}

Keywords: architectural heritage, unreinforced masonry, seismic base isolation, failure mode interaction surface.

\section{Introduction}

Seismic retrofitting of heritage masonry structures presents a challenging field. On the one hand its aim is to increase the seismic performance of the structure to a very small level of permissible risk, while on the other hand any remedial measures into such objects must be selected with care and should have minimum visual impacts. The standard goals of the seismic improvement of existing masonry buildings are the consolidation of the foundations and walls, establishing ties with sufficient stiffness between walls and between walls and floors, to achieve a global box-like behavior of the structure, and the implementation of safeguarding measures to prevent potential collapse mechanisms. In recent years the implementation of base isolation for the seismic mitigation of buildings has become a common alternative to conventional strengthening measures. In all over 16.000 structures have been protected in the world by seismic isolation, energy dissipation and other anti-seismic systems (Martelli et al., 2012). The majority of them are located in Japan, although they are more or less numerous in over 30 other countries. A base isolation system consists of a decupling isolation layer between the building and the ground. The isolation layer is made of devices that support the building against static actions and, in case of seismic actions, implement a decoupling effect of the dynamic response of the building compared to the ground. A base-isolated building is characterized by a smaller acceleration response, leading to a 
smaller amount of forces of inertia, a smaller amount of interstorey drifts and internal forces in structural elements.

The paper deals with base isolation as a seismic restoration technique for masonry buildings of heritage architecture. A case study in which base isolation is implemented in a typical neo-renaissance masonry building is presented and discussed.

\section{Equivalent frame modelling of masonry structures 2.1 Macro-element discretization}

Unreinforced masonry (URM) buildings are usually built of load-bearing masonry walls, arranged in different orthogonal planes and in most cases connected together by means of flexible diaphragms (timber floors). In a seismic event, the damage to masonry structures usually includes in- and out-of-plane failures of structural elements, which can be taken into consideration only if a comprehensive 3D model of the whole building is used (Belmouden and Lestuzzi, 2009). In general, masonry walls often incorporate irregularities in the form of an irregular layout of openings, so that special modelling considerations have to be taken into account (Parisi and Augenti, 2012). In the cases of irregular geometry a macro-element discretization of masonry elements is usually adopted, which is able to predict the seismic response with sufficient accuracy and with relatively low computational costs compared to those involved in the case of conventional nonlinear finite element modelling approaches (Calio et al., 2012).

\subsection{Masonry seismic failure modes}

The in-plane lateral resistance of URM buildings is provided by the piers and spandrels. In addition to the vertical force in the piers due to the dead loads, these resisting elements are under horizontal seismic actions at the base of the structure subjected to shear and bending. Depending on the width to height ratio of a masonry element and on the respective values of the normal force, bending moment and shear force, three failure mechanisms might be observed (Magenes and Della Fontana, 1998):

- Rocking failure mechanism in which the horizontal load produces tensile flexural cracking at the corners and the pier begins to behave as a rigid body rotating (rocking) about its toe.

- Diagonal cracking shear failure occurring with the formation of a diagonal crack that typically involves both the mortar joints and the masonry units. This failure mechanism is a result of several interacting factors, where the heterogeneity of masonry plays a dominant role.

- Shear sliding failure along a bed joint at one end of the structural element. This mechanism takes place only in piers. 


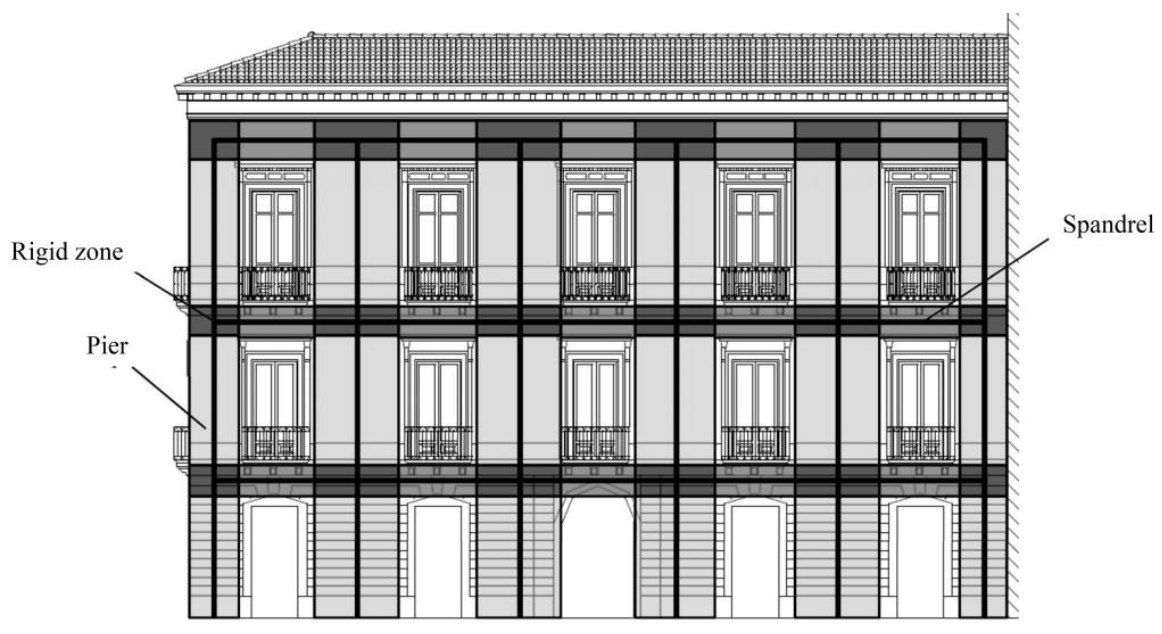

Figure 1. Equivalent frame of a three-story masonry wall (Liberatore et al., 1999).

\subsection{Seismic failure mode interaction}

In order to accommodate different failure modes in a simple and, in comparison with a comprehensive nonlinear shell finite-element model, computationally less demanding technique, the authors of the paper have proposed a new technique for the modelling and analysis of regular URM structures (Petrovčič and Kilar, 2013). This technique is based on the equivalent frame approach, and incorporates linear beam elements and the plastic hinge concept. The complex seismic failure mechanism of masonry piers is expressed by a single failure mode interaction surface (an "FMI surface"), taking into account the influence of variation in the pier's vertical loading, and its bending moment distribution. The ultimate lateral strength of a masonry element is expressed as a section which cuts through the FMI surface. A single failure mode interaction plastic hinge (an "FMI hinge") for each masonry frame element is introduced by combining specific failure modes, taking into account their minimum envelope. Figure 2 presents an example of FMI surface which shows the ultimate shear strength of a masonry peer $\left(V_{U}\right)$ for different axial force $N$, slenderness $\lambda$ and corresponding failure mode. The expressions describing their mathematical formulations are readily available in European building codes and elsewhere in the literature. More details could be found in (Petrovčič and Kilar, 2013).

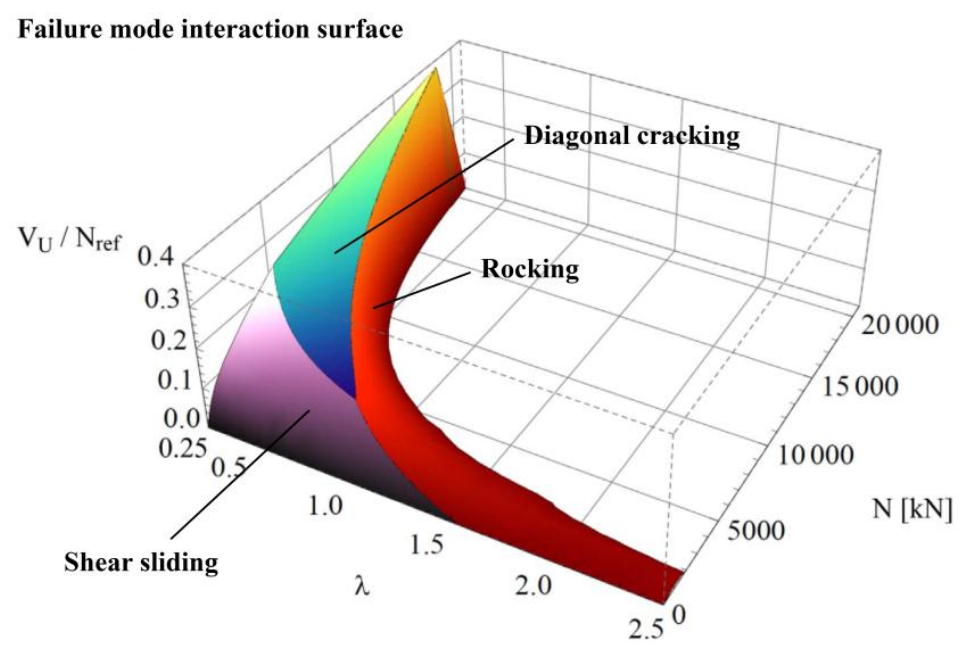

Figure 2. An example of a failure mode interaction surface of a masonry pier.

The accuracy of the proposed technique was confirmed by means of a comparative analysis of an URM wall assemblage which has already been studied by other researchers, using different 
modeling techniques and analysis software. In the paper at hand this modelling technique is applied for the analysis of a base-isolated URM building.

\section{Seismic base-isolation of masonry structures}

In comparison with new buildings, the seismic base-isolation of existing buildings is tied to some specific features. One particular issue is to define the maximum distance in plan between the isolators, basing it on the mechanical properties of the masonry (Mezzi et al., 2011). The problem of optimizing the placement of the center of stiffness to prevent torsion effects has already been studied by Kilar and Koren (2009a). Furthermore, the isolators behave as concentrated supports under continuous masonry walls: the positioning distance influences the stresses in the walls, the total amount of devices and their layout in plan. In order to redistribute the concentrated load of the devices, beams, stiffening the wall edges, must be built above and below the level of the isolators (Mezzi et al., 2011).

Installation issues and accessibility to the equipment for inspection, maintenance or replacement also present important factors for the installation of base-isolation in existing buildings. The masonry walls have to be decoupled from the foundation. This is done by using a diamond wire cutting saw or similar equipment (Bailey and Allen, 1988).Therefore to examine the quality of the walls rising from the foundations, to carry out any required consolidations and to define the most appropriate working demolition techniques, also with reference to the narrowness of the available spaces (Mezzi et al., 2011). As of today, existing applications of base isolation to existing masonry buildings are scarce. These applications generally focus on heritage buildings with strong preservation needs. One of the best known examples is The Salt Lake City and County Building in Salt Lake City, Utah, USA (Bailey and Allen, 1998). The building is a five story masonry structure with a large central tower, built in 1891. The isolation system consists of $239 \mathrm{NRB}$ (Natural Rubber Bearing) and 208 LRB (lead Rubber Bearings) isolators. Another example from the USA is The Hearst Memorial Mining Building in Berkeley, California (Davis and Robertson, 2000). The structure in question is a masonry building, built in 1907. It is located inside the Berkeley University campus that has been base isolated with 134 elastomeric devices. The largest of base-isolated masonry buildings are the headquarters of the New Zealand Parliament in Wellington, New Zealand (Poole and Clendon, 1992), which is a masonry building dating from the second decade of 1900. It has been base-isolated with 417 HDRB (High Damping Rubber Bearings) and LRB isolating devices

\section{Case study}

\subsection{Examined masonry building}

In the conducted case study a base-isolated masonry building typical for the neo-renaissance era in Europe was analyzed. The building is a three story unreinforced masonry structure with floor plan dimensions $24.6 \mathrm{~m} \times 12.9 \mathrm{~m}$ (directions $\mathrm{X}$ and $\mathrm{Y}$, respectively) and a total height of $15.8 \mathrm{~m}$. The examined masonry structure is schematically presented in

Figure . Detailed information regarding its geometry, mechanical parameters of masonry and modeling are presented in the paper by Petrovčič and Kilar, 2013. The structure can be divided into four different types of planar wall assemblies, i.e. Wx-1, Wx-2, Wy-1 and Wy-2. Each planar wall of the structure has been modeled based on the equivalent frame approach, using piers, spandrels and rigid zones as indicated in Figure. The story masses of the fixed-base structure (without base isolation) amount to $\mathrm{m}_{\text {base }}=878$ tons, $\mathrm{m}_{1}=748$ tons and $\mathrm{m}_{2}=499$ tons, whereas its fundamental periods are $\mathrm{T}_{\mathrm{X}}=0.39 \mathrm{~s}$ (in the $\mathrm{X}$-direction) and $\mathrm{T}_{\mathrm{Y}}=0.29 \mathrm{~s}$ (in the $\mathrm{Y}$-direction). 

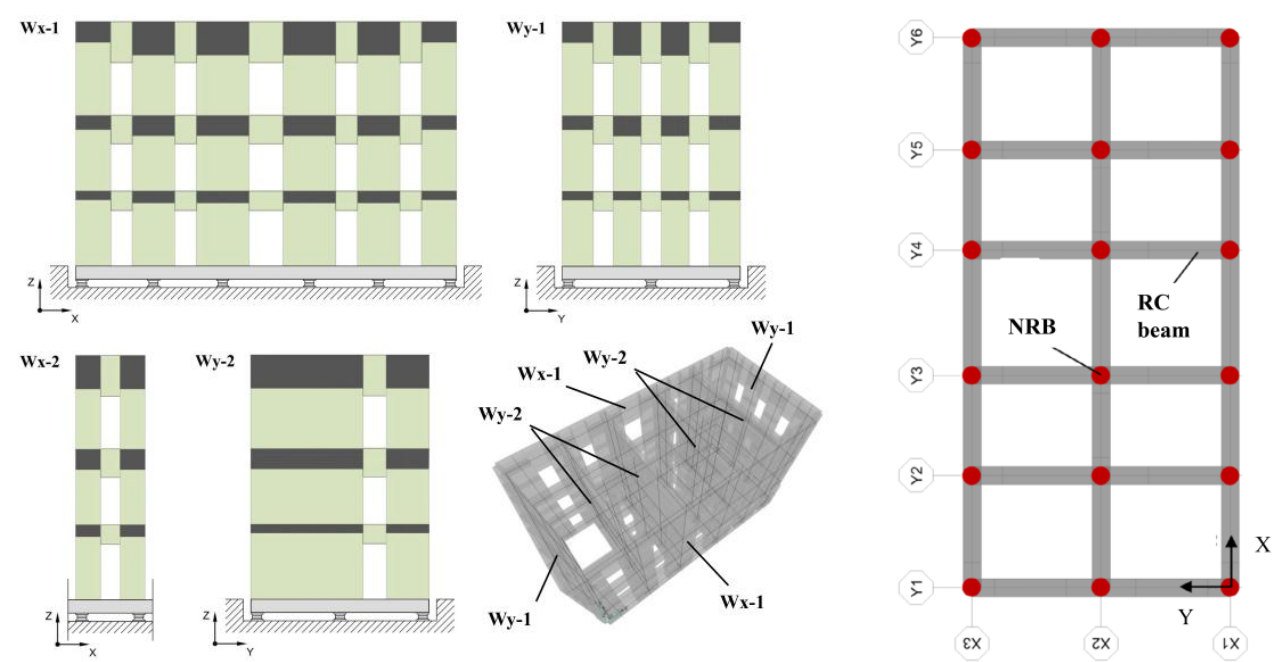

Figure 3. Examined masonry building (left) and the distribution of seismic isolators (right).

The building is located in a moderately active seismic area, with a design ground acceleration equal to $a_{g}=0.25 \mathrm{~g}$ and a soft soil site that corresponds to sub-soil of class $\mathrm{C}$ in accordance with Eurocode 8-1 (CEN, 2005). Through a preliminary pushover analysis of the fixed-base structure it has been determined that the behavior factor of the building equals to $q=2.5$ for the X-direction of seismic loading and $q=2.2$ for the Y-direction (Petrovčič, 2013).

\subsection{Selected base isolation system}

A base isolation system consisting of natural rubber bearings (NRB) has been selected and implemented in the analyzed mathematical model for the examined building. Since the fundamental periods of vibration lie in the constant acceleration branch of the Eurocode 8 type 1 response spectrum, a seismic force reduction factor equal to the maximum behavior factor of the building ( $R=q=2.52$ ) has been selected as the input parameter for the design of rubber bearings. A total of $18 \mathrm{NRB}$ have been selected and inserted at the foundation level and positioned in an orthogonal grid as presented in

Figure. The NRBs have a diameter of $60 \mathrm{~cm}$ and a height of $15 \mathrm{~cm}$ (height of rubber equal to $8 \mathrm{~cm}$ ). They are made of soft rubber and have a horizontal stiffness of $2830 \mathrm{kN} / \mathrm{m}$, with damping equal to $\xi=10 \%$ of critical damping. Their maximum horizontal displacement is equal to $15 \mathrm{~cm}$, which is about $200 \%$ of the height of the rubber. To ensure a uniform distribution of stresses onto the base isolation system RC beams has also been designed and implemented in the model.

\subsection{Analysis of seismic performance}

The seismic performance of two variants has been analyzed: (i) a fixed-base (FB) variant without base isolation and (ii) a base-isolated (BI) variant. Non-linear static (pushover) analyses have been carried out. The pushover analysis has been conducted to the formation of the plastic mechanism. The target displacement of the analysed models has been determined by using the $\mathrm{N} 2$ method for base-isolated structures, developed by Kilar and Koren (2009b). It represents the so called "earthquake demand", that is the displacement the given base-isolated structure will obtain when subjected to a seismic event characterized by a given set of seismic parameters.

Figure obtained damage patterns for the design ground acceleration $a_{g}=0.25 \mathrm{~g}$ are presented. In the figure the failure mechanism and the state of damage for specific masonry elements (piers and spandrels) are shown by colour (indicating the damage) and by symbol (indicating the type of 
formed failure mechanism). Three discrete limit states in accordance with Eurocode 8-3 are observed, i.e. damage limitation (DL), indicating no or slight damage, significant damage (SD) and near collapse (NC). It can be seen from Figure 4 that for the selected base isolation the damage is significantly reduced in caparison with fixed based building.

It can be seen that the damage limitation state (DL) has not been exceeded for any pier and that some minor damage remains only in the upper stories. It can be also seen that the usage of proposed URM surface enables a better insight in the damage and failure mode of a masonry units which enables a designer to tune the response of a building exactly to the wishes and needs of conservation plans provided by architects and conservation experts.

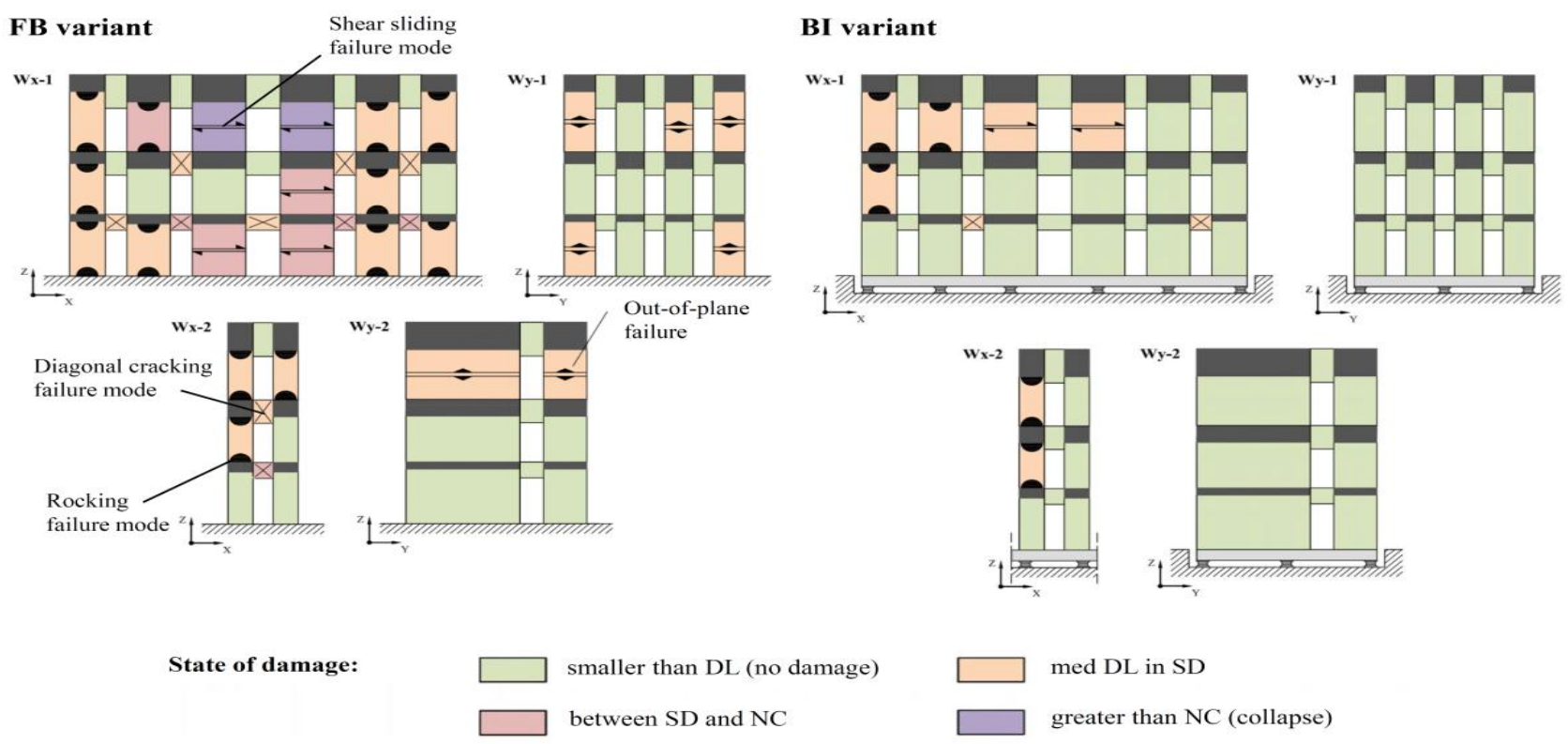

Figure 4. Comparison of sustained damage for the design seismic loading corresponding to the design ground-motion intensity $\left(a_{g}=0.25 \mathrm{~g}\right)$

\section{Conclusion}

The use of base isolation can be a valuable tool for increasing of seismic resistance of architectural heritage buildings. Installation issues and accessibility to the equipment for inspection, maintenance or replacement at the moment limit the practical usability of base isolation only to extremely important building where additional costs of such measures can be justified. In the first part of the paper complex seismic failure mechanisms of URM piers have been expressed by a single failure mode interaction (FMI) surface showing the relations between the pier's ultimate lateral strength $\mathrm{Vu}(\mathrm{N}, \lambda)$ with respect to its axial force variation $\mathrm{N}$, and its geometry expressed by the slenderness ratio $\lambda$. In the continuation of the paper it has been shown how the FMI surface can be used for mathematical modelling purposes and how a pier's lateral strength in terms of the $\mathrm{N}-\mathrm{V}$ interaction can be expressed as a section cut through the FMI surface, considering the pier's ג). Using the SAP2000 computer program, a refined modelling approach for the inelastic behavior of piers has been defined. The last part of the paper presents a case study in which a base isolation system has been used as a seismic restoration technique for a historical masonry building. The analyzed structure has been modeled by using a macro-element frame model with the failure mode interaction surface to model the nonlinear response of masonry elements under seismic 
loading. In this approach a single combined plastic hinge that includes the interaction between the flexural, shear and diagonal failure modes with respect to the vertical (axial) load in a masonry element is used. Two variants of the building have been studied. First the initial variant has been studied, which does not have base isolation or any other conventional strengthening technique applied. The second variant is base-isolated with rubber bearings. The results of a comparative pushover analysis have shown us that a base isolation system can dramatically decrease the damage caused by a seismic event on such structures. Furthermore, the installation of a base isolation layer requires minimum interventions in the original structure, since such a system is usually installed at the foundation level.

\section{References}

Bailey, J. S. and Allen, E. W. (1988). Seismic Isolation Retrofitting - Salt Lake City and County Building. APT Bulletin. 20(2): 33-44.

Belmouden, Y., Lestuzzi, P. (2009). An equivalent frame model for seismic analysis of masonry and reinforced concrete buildings. Construction Building Materials. 23(1): 40-53.

Calio, I., Marletta, M., Panto, B. (2012). A new discrete element model for the evaluation of the seismic behaviour of unreinforced masonry buildings. Engineering Structures. 40: 327-38.

CEN (2005). Eurocode 8: Design of structures for earthquake resistance - Part 1: General rules, seismic actions and rules for buildings, EN 1998-1. European Committee for Standardization, Brussels.

Davis, H.A., Robertson, D.R. (2000). Hearst Memorial Mining Building Seismic Improvements, University of California, Berkeley. Proceedings of the $12^{\text {th }}$ World Conference on Earthquake Engineering, Auckland, paper 1636.

Kilar, V., Koren, D. (2009a). Seismic behaviour of asymmetric base isolated structures with various distributions of isolators. Engineering Structures. 31(4): 910-921.

Kilar, V., Koren, D. (2009b). Simplified inelastic seismic analysis of base-isolated structuresusing the N2 method. Earthquake Engng Struct. Dyn. 39(9): 967-989.

Liberatore, D., Beolchini, G., Binda, L., Gambarotta, L., in Magenes, G. (1999). Valutazione della risposta sismica del costruito in muratura del Comune di Catania. Proc. of the 9 th National ANIDIS Conference, Torino.

Magenes, G., Della Fontana, A (1998). Simplified non-linear seismic analysis of masonry buildings. Proceedings of the Fifth International Masonry Conference, London: 190-195.

Martelli, A., Clemente, P., Saitta, F., and Forni, M. (2012). Recent worldwide application of seismic isolation and energy dissipation to steel and other materials structures and conditions for their correct use. STESSA 2012, 1(1), London: 1-12.

Mezzi, M., Comodini, F., in Rossi, L. (2011). A Base Isolation Option for the Full Seismic Protection of an Existing Masonry School Building. Proceedings of the Thirteenth International Conference on Civil, Structural and Environmental Engineering Computing, 1(1), Stirlingshire: 1-14.

Parisi, F., Augenti, N. (2012). Seismic capacity of irregular unreinforced masonry walls with openings. Earthquake Engineering and Structural Dynamics, 42(1): 101-21.

Petrovčič, S., Kilar, V. (2013). Seismic failure mode interaction for the equivalent frame modeling of unreinforced masonry structures. Engineering Structures. 54: 9-22.

Petrovčič, S. (2013). Seismic base isolation as a system for earthquake mitigation of architectural heritage. PhD Thesis. University of Ljubljana, Faculty of Architecture, Ljubljana, 286 p.

Poole, R.A., Clendon, J.E. (1992). New Zealand Parliament Buildings Seismic Protection by Base Isolation. Bulletin of the New Zealand National Society for Earthquake Engineering, 25(3): 147-160. 